\title{
Monocórdio: contextualizando a Matemática por meio da Música
}

\author{
Monocord: contextualizing Mathematics by means of the Music
}

\author{
Ross Alves do Nascimento \\ Universidade Federal Rural de Pernambuco (UFRPE), Recife, PE, Brasil \\ ross.n58@gmail.com
}

\begin{tabular}{l}
\hline Informações do Artigo \\
\hline cc) (†) \$ \\
\hline
\end{tabular}

Histórico do Artigo

Submissão: 31 de março de 2018.

Aceite: 26 de junho de 2018.

\section{Resumo}

O objetivo desse trabalho é apresentar ações de contextualização da Matemática evidenciadas em uma atividade de construção da escala musical por estudantes do Ensino Médio usando um Monocórdio. Exploramos a contextualização da Matemática a partir de uma vivência realizada com 32 alunos de uma Escola Estadual do Recife com a colaboração de 05 (cinco) estudantes da disciplina de Prática de Ensino da Matemática II ministrada na Universidade Federal Rural de Pernambuco (UFRPE), no semestre 2012/1, como observadores. A atividade está ligada às várias ações do ambiente de pesquisa LACAPE - Laboratório Científico de Aprendizagem Pesquisa e Ensino, do Departamento de Educação da UFRPE, o qual congrega a elaboração e testagem de material didático, projetos de pesquisa e extensão, formação de professores, entre outras ações da Educação Matemática. Na Educação Matemática se discute que o processo de contextualização deve estar associado aos conhecimentos estudados e orientar a aprendizagem (BROUSSEAU, 1996; PAVANELLO, 2004). Tal processo é percebido nas atividades interdisciplinares e de Modelagem Matemática. Portanto, ao usar o Monocórdio como recurso para construção da escala musical colocando os estudantes diante da associação dos saberes matemáticos ligados à música, buscamos reproduzir as notas da escala musical com atividade semelhante a que foi usada por Pitágoras. Os alunos trabalharam em grupos e utilizaram um Monocórdio, régua e desenho de um teclado. Os resultados indicam valorização do contexto a partir da Matemática necessária ao modelo de escala construído, discussão de saberes prévios utilizados e requisitou habilidades necessárias à percepção das notas musicais atreladas à frequência de som produzida no Monocórdio.

\author{
Keywords \\ Contextualization \\ Mathematical Modeling \\ Monochord \\ Mathematics Teaching
}

\section{Abstract}

The objective of this work is to present contextualization actions of Mathematics evidenced in a musical scale construction activity by high school students using a Monochord. We explored the contextualization of Mathematics from an experience with 32 students from a state school in Recife with the collaboration of 05 (five) students of the Mathematics Teaching Practice II course at UFRPE / 2012.1, as observers. The activity is linked to the various actions of the research environment LACAPE Scientific Laboratory of Learning Research and Teaching, of the Department of Education of UFRPE, which brings together the preparation and testing of teaching materials, research and extension projects, teacher training, among other actions of Mathematics Education. In mathematics education, it is argued that the contextualization process must be associated with the knowledge studied and guide learning (BROUSSEAU, 1996; PAVANELLO, 2004). This process is perceived in Interdisciplinary and Mathematical Modeling activities. Therefore, when using the Monochord as a resource for the construction of the musical scale putting students before the association of mathematical knowledge linked to music, we seek to reproduce the notes of the musical scale with activity similar to that used by Pythagoras. The students worked in groups and used a Monochord, ruler and drawing of a keyboard. The results indicate the valorization of the context provoked from the mathematical 
knowledge necessary to the constructed scale model, the discussion of the type of previous knowledge to be used and requested abilities to perceive the musical notes linked to the frequency of sound produced in the Monochord.

\section{Introdução}

No ensino básico da Matemática, apesar de existir diversas metodologias que podem ser utilizadas no sentido de minimizar as dificuldades de aprendizagem, ainda se discute um ponto comum, que é como operacionalizar boas estratégias de ensino aprendizagem para os estudantes (BORIN, 1996; FLAVELL, 1976; SKOVSMOSE, 2001). Esse problema, relativo ao ensino de Matemática, pode estar relacionado a uma ausência de contextualização, recurso usado no ensino aprendizagem para verificação, validação e compreensão do uso do conhecimento matemático. Esse recurso é importante e tem implicação na aprendizagem dos estudantes e com valor significativo a partir do momento inicial da preparação do material a ser usado que o professor elabora para suas atividades didáticas, no qual busque sempre contemplar contextos para valorizar a aprendizagem. Skovsmose (2001) destaca que o ensino de Matemática deve ter significado para o aluno, que envolva a participação, discussão e conhecimento da relação dessa ciência com o cotidiano. A partir desse foco, é importante se discutir estratégias que possam ser utilizadas na sala de aula para contextualizar o conhecimento matemático.

Buscando analisar procedimentos de contextualização da Matemática, realizamos um experimento utilizando um Monocórdio (instrumento musical de uma só corda), como material didático, no sentido de motivar estudantes do Ensino Médio para compreensão, aplicação e interpretação de suas ações, quanto à percepção do tipo de matemática que seria necessário para a construção do modelo da escala musical (Dó, Ré, Mi, Fá, Sol, Lá, Si). Os processos de contexto e contextualização explorados para a Matemática nessa situação têm discussões bem presentes sobre a forma como deve ser tratado o ensino, como observado nas orientações dos PCN (BRASIL, 1998), e nas Diretrizes e Bases da Educação Nacional (LDBEN) 9.394, (BRASIL, 1996), ou seja, tratado como um mecanismo que participa da aprendizagem dos alunos ao buscar construir um conhecimento, aprendizagem essa que the dê significado. Assim, o estudante ao reconhecer situações-problema tanto do ensino escolar quanto do seu cotidiano que estejam repletas de contexto que ele um dia trabalhou é um processo que vai valorizar sua aprendizagem. A contextualização passa a ser tratada como um mecanismo de ilustração do saber matemático, ou seja, dando-lhe um sentido, como discutido também nas Orientações Curriculares Nacionais (BRASIL, 2006, p. 83).

Para esse tipo de atividade, algumas metodologias, hoje empregadas pelos professores, oferecem situações em que o contexto é fundamental e em muitos casos estão ligadas ao processo de aprendizagem trabalhado. A técnica de modelagem matemática é uma delas, pois há situações que o estudante precisa explorar uma matemática relacionada a um contexto para construção de um modelo. A Modelagem Matemática deveria ser uma prática mais frequente nas escolas, pois 
incorpora um processo de compreensão e utilização dos conhecimentos que são adquiridos pelo aluno, prática essa que é bastante discutida em várias pesquisas (BASSANEZI, 2002; FRANCHI, 1993; NASCIMENTO; GITIRANA, 2011).

No nosso estudo, para a realização da atividade, os alunos investigados deveriam elaborar o modelo de escala musical e fazer a testagem da mesma a partir de um instrumento didático oferecido, o monocórdio. Ou seja, deveriam apresentar como foi construído o modelo a partir dos dados que produziu, dos cálculos que utilizou e dos conceitos matemáticos que fez uso e que foram necessários para compor a construção da escala musical. Nesse tipo de situação a construção do modelo requisita saberes matemáticos que devem ser tratados pelo grupo de estudantes envolvidos, que envolve um processo de contextualização do saber matemático. Esses dados seriam gerados a partir da compreensão correta de divisão fracionária na manipulação do Monocórdio, pois os alunos para compor o modelo necessitariam de saberes matemáticos que estavam participando de um processo de contextualização. Portanto, a atividade se resumia a criar um modelo da escala cromática destacando os saberes matemáticos necessários para construção dessa escala percebendo a necessidade do saber e esquema matemático a empregar, ou seja, realizar de forma correta as divisões fracionárias do comprimento de uma corda sonora, no sentido de escalonar em ordem sequencial de som (agudo crescente), como processo de contextualização da Matemática que é requisitada.

O objetivo do trabalho foi vivenciar o uso do Monocórdio como recurso para contextualização da Matemática. A Matemática a ser utilizada para entender a construção do modelo da escala requisitado estaria associada à divisão de frequência de som e reagrupamento dos sons musicais que soam de forma agradável ao ouvido humano, como é a escala cromática. Nesse sentido, buscamos identificar que habilidades os alunos utilizavam no sentido de entender a entonação das notas musicais produzidas e exploradas no Monocórdio, verificar se percebiam o reforço do contexto relacionado as áreas Matemática e Música.

Um fato que levamos também em conta foi se existiria dificuldade na valorização do trabalho, pois o contexto oferecido para a Matemática a partir do uso de um instrumento desconhecido, o Monocórdio, em um experimento não comum na escola, seria um fator negativo. A questão da existência de dificuldade de valorização do contexto reside no fato de que muitos problemas propostos nos livros didáticos, oferecidos aos alunos, buscam trabalhar uma Matemática a partir de situações que lhe dê um significado da realidade vivenciada, ou seja, uma forma de contextualizar, mas esse processo é tratado pelo aluno unicamente valorizando os procedimentos que precisa aplicar, ele muitas vezes descarta o contexto que na situação é evidente, ficando preocupado puramente com os processos matemáticos exigidos, de forma que a força do contexto oferecido não é muito significativa, sendo esse um ponto que deve ser discutido quanto ao uso de contexto na Matemática. 


\section{A Importância da História da Matemática como Contexto}

A partir da observação do universo, o ser humano começa a estudar os fenômenos naturais, propondo para si a busca pela compreensão de todos os fatos que envolvem a Terra e o Espaço. Perceber como são caracterizados os corpos celestes, identificar na natureza as possibilidades de catástrofes, conhecer e identificar as leis naturais, entre outras ações, é um tipo de situação que passou a ser incorporado no seu modo de vida cotidiano e de estudo. As produções dessa prática vivenciada desde as primeiras civilizações retratam dados significativos que levaram matemáticos e pensadores da antiguidade a construir um registro de todo o saber produto dessas compreensões, esses fatos estão registrados em livros sobre História da Matemática (AABOE, 2002; BOYER, 1974; EVES, 1997).

Os povos antigos são referências dessa prática, a partir daquilo que construíram e deixaram como marco histórico das ações iniciais do homem, destacando-se nessa época os Babilônios, Egípcios, Gregos, Chineses e tantos outros. Nesse período, se verifica que observar a natureza era o caminho que proporcionava entender leis que validavam muitos saberes matemáticos que estavam sendo formalizados. Essa construção matemática a partir da história é hoje tratada como instrumento de contexto histórico da Matemática. Vasconcellos (2008, p. 49) destaca que "contextualizar é apresentar em sala de aula situações que dêem sentido aos conhecimentos que desejamos que sejam aprendidos, [...] resgatando os conhecimentos prévios e as informações que os alunos trazem, criando, dessa forma, um contexto que dará significado ao conteúdo", de modo que esse processo possa conduzir o aluno a compreender a Matemática envolvida e relacioná-la ao seu dia a dia.

Um ponto a se destacar na produção cultural dos Gregos é a Escola Pitagórica, que dava extrema importância ao conhecimento matemático. Abdounur (2007) faz um destaque dessa Escola, citando o fato de que, ao manipular matematicamente a acústica, conseguiram perceber, por associação das consonâncias musicais, que existiam cálculos de razões simples (proporcionalidade), envolvendo valores numéricos 1, 2, 3, 4 etc., que estavam associados a uma construção harmônica do som. Dessa forma, notaram que poderiam expressar conceitos teóricos e até mesmo a existência de uma harmonia cósmica por meio da Matemática.

\section{O Material Didático do Professor}

Muitos professores, principalmente aqueles em início de carreira, costumam utilizar apenas os tópicos metodológicos oferecidos nos livros didáticos (PNLD). Que começaram a ser enriquecidos de páginas introdutórias que expõem um pouco de História da Matemática, colocando esse professor diante da tarefa de explicar aos alunos como ocorreram tais fatos. Essa proposta requer do professor, em algumas situações, que possa levantar discussões, construir e elaborar materiais a partir de orientações oferecidas nos tópicos de ensino a ser estudados, ou seja, buscam compor os conteúdos com um pouco de contextualização da Matemática. Portanto, algumas 
atividades passam a ser motivadoras tanto a professores quanto aos alunos. Essas propostas didáticas, muitas vezes, são as únicas que são oferecidas aos alunos para contextualização do saber matemático. A falta de contextualização no ensino pode trazer consequências e até dificuldades aos alunos, pois em muitos casos, necessitam desse recurso para valorizar suas aprendizagens e até para entender como ocorre a aplicação do conhecimento matemático.

A falta de exploração da contextualização da Matemática está em muitos casos relacionados à formação do professor, quando na sua graduação não se percebe essa forma de vivência que deverá ser explorada em sua prática e que pouco aparece no material utilizado para sua formação, sendo pouco discutida. Dessa forma, a maneira como os conteúdos devem ser explorados e transmitidos não pode deixar de lado lições importantes que valorizem a aprendizagem dos alunos por meio de contextos. Muitas das sugestões oferecidas nos livros didáticos sugerem processos de confecção e elaboração de materiais, no sentido de estimular os alunos à entenderem parte das estruturas da Matemática.

\section{Utilização de Materiais Didáticos no Ensino de Matemática}

Não discutiremos aqui sobre Ábaco, Base Dez ou Blocos Lógicos, mas sobre um instrumento musical que pode ser utilizado para se observar a importância do contexto na Matemática, por meio da construção do modelo da escala musical. Construir a escala a partir da sonoridade de um Monocórdio, que é um instrumento musical composto de apenas uma corda (tratado como embrião do violão moderno), como apresentado na Figura 1 (Seção 5), propõe situações de ensino que envolve contextos. Tal instrumento, ao ser explorado, apresenta uma riqueza de conhecimentos que podem contribuir na aprendizagem dos estudantes a partir do contexto oferecido para vários conteúdos matemáticos, destacando-se a multiplicação, divisão, arredondamento de números, cálculo de frações, sequências numéricas, ordem numérica, escala, análise na reta, progressões, estudo de funções, logaritmo, entre outros.

O caderno dos PCN (BRASIL, 1997) destaca tanto a contextualização como proposta de extrema importância a ser explorada pelo professor, pois coloca os alunos diante de associação aos conteúdos que lhe são apresentados, como algo que aprende e que se percebe o aprendido conectado a situações reais. Vivenciar e valorizar a contextualização da matemática é uma ação defendida em várias pesquisas (BROUSSEAU, 1996; DEMO, 2004; PAVANELLO, 2004).

O experimento com o Monocórdio é uma proposta que deve provocar nos alunos investigados uma expectativa diferente, pois não é comum tal situação na escola. Nesse caso a contextualização dos saberes matemáticos envolvidos é mais significativa. Pitágoras, ao valorizar a importância da música na aprendizagem, realizou a compreensão da relação entre o comprimento de uma corda vibrante e o tom musical produzido por ela, construindo todo um formato de conexões entre conhecimento matemático e música, ou seja, um modelo que representa essa relação. Tal experimento é caracterizado como a primeira lei descoberta empiricamente (primeira experiência 
registrada na história da ciência, no sentido de isolar algum dispositivo para observar fenômenos de forma artificial), segundo Abdounur (2007).

O trabalho com o Monocórdio, a ser experimentado no nosso estudo iniciou com uma discussão a partir do conhecimento preliminar dos alunos sobre a escala musical em sua composição mais simples e que eles certamente identificaram como sendo Dó, Ré, Mi Fá, Sol, Lá, Si. Nesse modelo preliminar estão indicados apenas os tons da escala sem as particularidades e suas propriedades. Essa foi a base de conhecimento de onde partimos em relação ao conteúdo musical e o sentido de audição de cada aluno ao fazer vibrar a corda do Monocórdio para identificar um som.

\section{Metodologia}

Duas questões são importantes destacar: a primeira é o fato de escolha da atividade, que envolvia saberes relativos à Música. Isso foi possível por conta de uma conversa comum entre os cinco alunos e o professor quando se descobriu que dois dos alunos da disciplina de "Prática de Ensino da Matemática II" e o professor da disciplina, autor do trabalho, tinham conhecimentos básicos em Música, fato esse gerado por um dos alunos chegar um dia na sala de aula com um violão. A segunda informação é que na realização do experimento teríamos dois grupos de alunos que serão diferenciados por:

- Estudantes, quando nos referimos aos 05 (cinco) alunos: Delano Pereira, Aliege Menezes, Hailton Raposo, Josemir Ferreira e José Xavier, todos do curso de Licenciatura em Matemática que participaram acompanhando a atividade, pois pesquisavam sobre contexto na Matemática para realização de um seminário a ser realizado na disciplina "Prática de Ensino da Matemática II" da UFRPE.

- Alunos, quando nos referimos aos 32 (trinta e dois) alunos que participaram como sujeitos e que são do $2^{\circ}$ ano do Ensino Médio da Escola Estadual de Referência Professor Cândido Duarte, escola próxima ao Campus da UFRPE, em Recife.

Portanto, a atividade foi realizada com 32 alunos de uma turma do $2^{\circ}$ ano do Ensino Médio de uma escola pública da cidade de Recife. A escola tem horário integral, com as atividades de estudo das disciplinas realizadas no turno da manhã e as atividades experimentais e de estudo complementar no turno da tarde.

Iniciamos previamente um primeiro contato com a direção da escola e o professor da turma, expondo que se tratava da realização de um evento experimental do Laboratório de Pesquisa, conhecido como LACAPE/UFRPE, e que o processo envolvia noções de Matemática e Música. Essa escola é tida como uma escola de "aplicação" da UFRPE, pois, de certa forma, desde a sua fundação tem uma relação de troca de saberes pedagógicos entre o Governo Estadual e a própria 
Universidade, com livre trânsito aos pesquisadores, desde que não prejudique o andamento dos trabalhos dos professores da escola.

Comunicamos que a atividade seria realizada no turno da tarde e que precisávamos do envolvimento dos alunos do Ensino Médio para a realização da mesma, por um período de $2 \mathrm{~h} / \mathrm{a}$. Não destacamos que tipo de conhecimento específico estava envolvido, metodologia a ser empregada ou o que realmente estávamos buscando perceber. Ou seja, não discutimos sobre Contextualização ou Modelagem Matemática.

Na realização da atividade, apresentamos aos alunos dois instrumentos: um violão e alguns monocórdios simples (placas de madeira retangulares com pelo menos $60 \mathrm{~cm}$ de comprimento por $8 \mathrm{~cm}$ de largura, com dois parafusos nas extremidades para se esticar uma corda de violão, apresentando afinação de uma nota musical), como representado na Figura 1.

Figura 1 - llustração de um monocórdio.

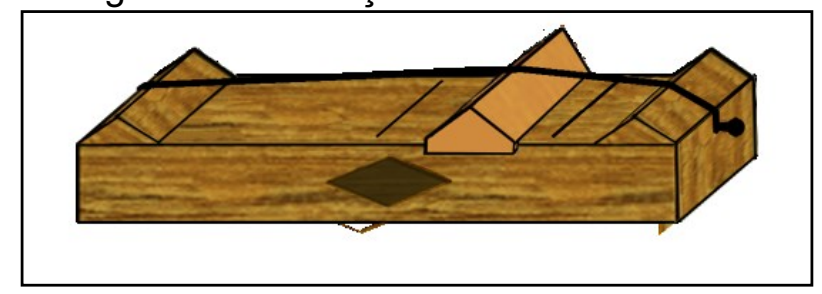

Fonte: Clubes de Matemática da OBMEP. Disponível em:

http://clubes.obmep.org.br/blog/aplicando-a-matematica-basica-construcao-de-um-monocordio/.

Cada grupo de alunos recebeu um monocórdio, uma régua, um pequeno texto com a presença de um pequeno teclado de piano para representar a posição das notas que deveriam perceber ao tocar o instrumento, papel para rascunho e lápis. Esses materiais foram sugeridos para utilização como meio de registros que na maioria dos casos seria necessário, como medição da corda do Monocórdio e das subdivisões que necessitassem fazer e para realização dos cálculos, foi indicado que eles poderiam utilizar os celulares como calculadora.

Figura 2 - Estudantes reunidos em grupo elaborando a atividade.

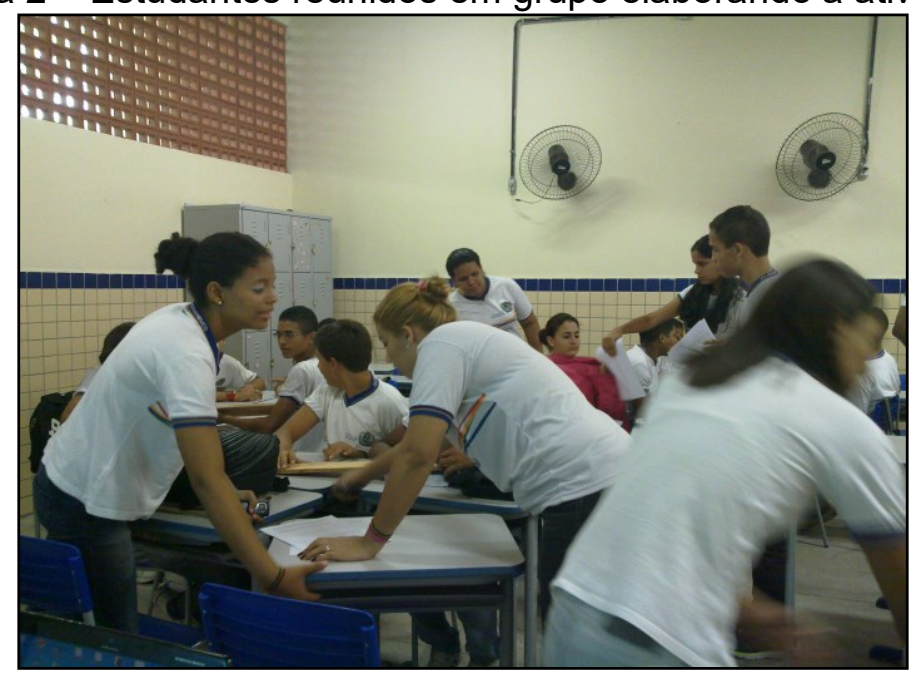

Fonte: Material da pesquisa. 
A orientação para os alunos foi que formassem grupos de trabalho, e que cada grupo deveria construir a escala de notas musicais a partir da manipulação desse instrumento, desconhecido por eles, o Monocórdio. Não destacamos que o processo buscava a percepção de contextos da matemática ou que estávamos modelando a construção da escala musical.

O experimento de Pitágoras com o Monocórdio partiu da memorização do som a partir da vibração da corda (primeiro tocando a corda solta), depois prendeu a corda na metade e tocou novamente, depois prendeu na terça parte e tocou, e por último prendeu na quarta parte e tocou. Pitágoras percebeu que alguns sons combinavam, ou seja, soavam harmonicamente aos ouvidos e outros não.

A escala musical é construída a partir de um processo básico, que envolve a fração 2/3 multiplicada ao comprimento da corda para se chegar a uma nota correspondente ao intervalo de quinta justa (sete semitons acima do tom original). Após a realização de sucessivas multiplicações, os estudantes estariam de posse de todas as notas da escala. O processo consistia em encontrar os valores e as notas (construir o modelo - um quadro ou gráfico que correspondesse aos valores de comprimento de corda). Nesse tipo de atividade, a localização das notas Dó ou Fá é um fator importante para que o aluno possa encontrar de imediato as notas naturais da escala.

Figura 3 - Representação de subdivisão da corda do Monocordio indicando as notas Dó, Sol e Fá.

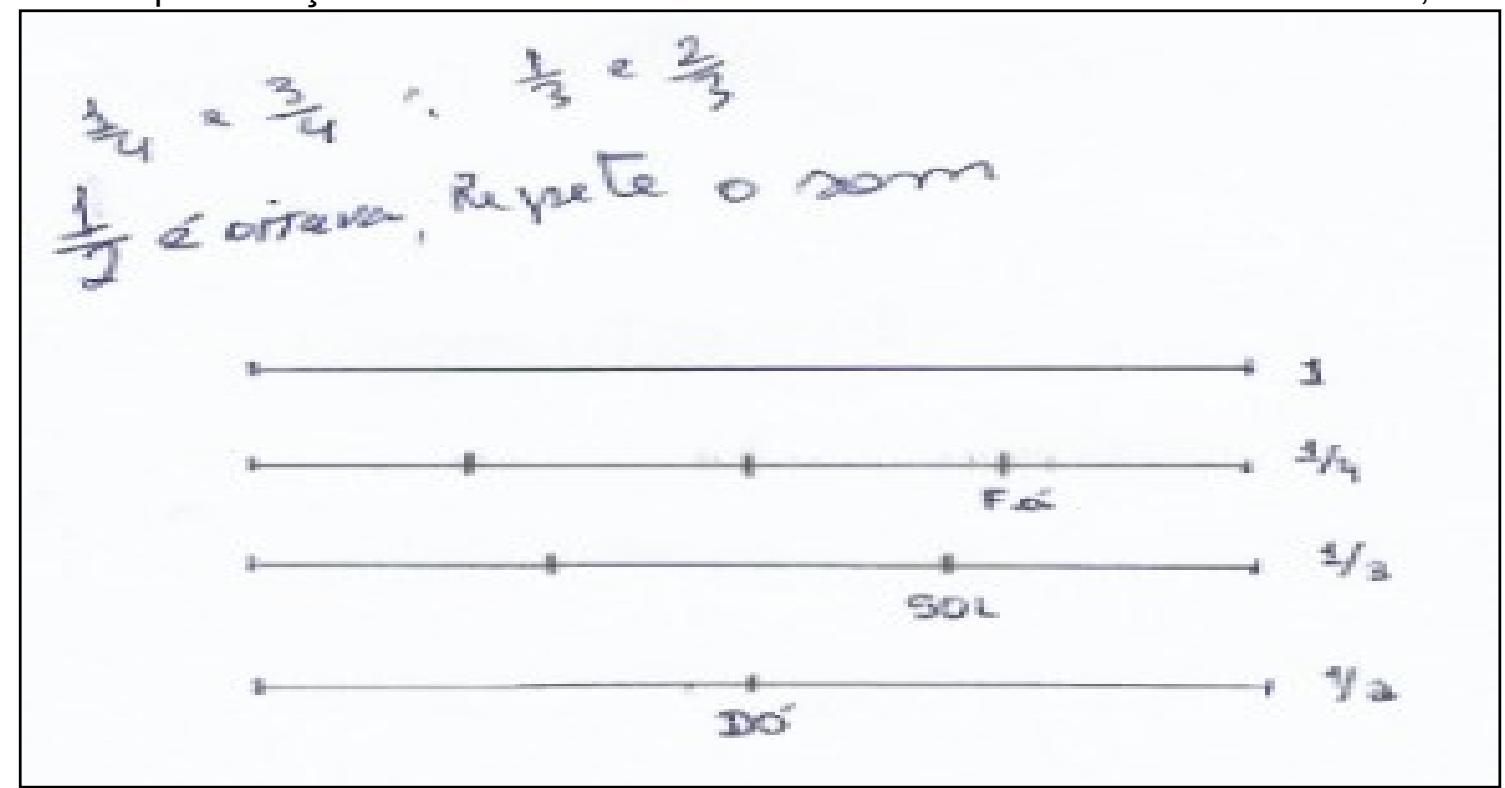

Fonte: Esquema elaborado por um dos grupos pesquisados durante a atividade.

Para cada divisão realizada em cada grupo de alunos foi solicitado que observassem a sonoridade das notas encontradas (aguda, grave), no sentido de compreender o intervalo de uma oitava - espaço compreendido para as sete notas da escala.

Como validação dos valores de nota que encontravam, podiam valorizar a compreensão da atividade utilizando um violão que também foi levado para a escola pois fazia parte dos instrumentos a ser utilizados no estudo. Nessa fase alguns grupos puderam comprovar se as notas tocadas no 
violão correspondiam às que foram marcadas por eles a partir do Monocórdio. Nesse caso, destacase um processo chamado 'de ouvido', que é utilizado por profissionais e conhecedores de música para o fato de se conhecer ou identificar um som a partir de instrumentos diferentes.

Figura 4 - Anotações dos alunos de um dos grupos para construção do modelo de escala musical.

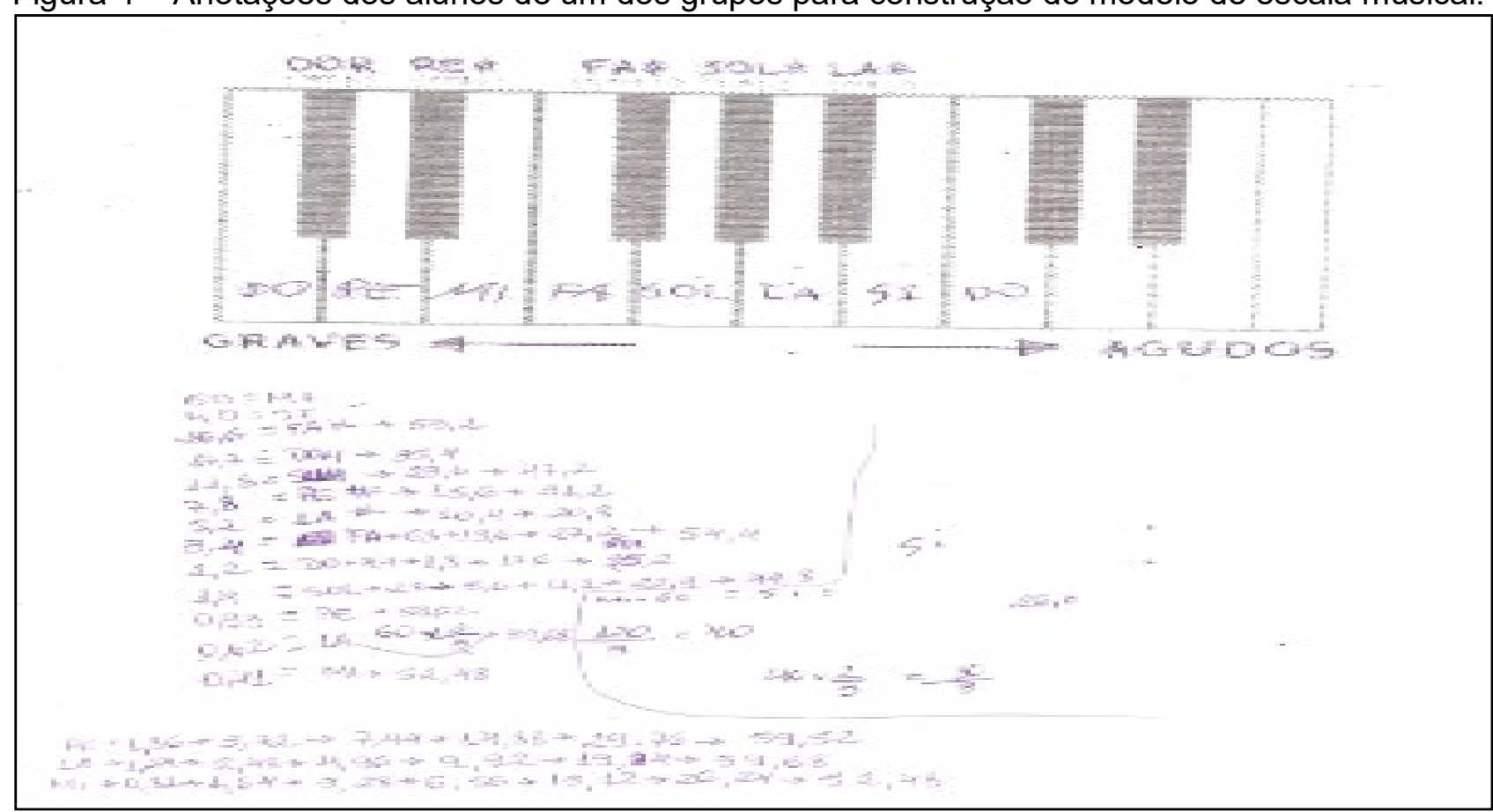

Fonte: Material produzido como registro por um dos grupos participantes.

\section{Participação dos Estudantes de Prática II}

O grupo de cinco estudantes da disciplina de Prática II tiveram uma aula sobre o que é contextualização do saber matemático e tínhamos também discutido sobre o tema a partir dos materiais didáticos do LACAPE, local de realização das aulas da disciplina "Prática de Ensino da Matemática II".

A participação dos estudantes da disciplina de Prática II na atividade foi de acompanhar, analisar e procurar entender de forma prática todo o processo que estava ocorrendo nos grupos durante a realização da atividade de contextualização da matemática envolvida. Decidimos anteriormente que eles não podiam interferir ou auxiliar os alunos investigados com alguma informação sobre a atividade, apenas acompanhar e sutilmente coletar dados que considerassem importantes para discutir posteriormente. Foram também orientados a elaborar previamente cinco perguntas que seriam aplicadas após o encerramento da atividade com os alunos do Ensino Médio. As questões foram sobre o que os alunos do Ensino Médio acharam da atividade. Tais perguntas e respostas estão apresentadas a seguir e também foram posteriormente discutidas no seminário.

1. Vocês acham que a matemática e a música têm alguma relação? Qual?

A resposta foi afirmativa. Com destaque para:

a. Quando precisaram executar a medição da corda para identificar a nota correta e colocar na ordem para formar a escala; 
b. Compreender que fração da corda estava relacionada ao som emitido;

c. Qual a medida da corda a ser presa (fração), para gerar o som a ser representado em sequência pela altura (sonoridade), para formar a escala corretamente;

d. Que havia uma relação entre a nota da fração $1 / 2$ da corda com a nota da corta solta.

2. Vocês visualizaram algum saber matemático importante na construção da escala musical? O destaque foi sobre divisão, multiplicação, entender o valor dos números fracionários, identificar uma sequência por sonoridade (ordenação das notas).

3. Vocês perceberam alguma complexidade na representação da escala musical?

As respostas variam entre sim e não, pelo fato de que alguns grupos tinham se saído melhor que outros na realização da tarefa.

4. Vocês têm interesse nesse tipo de atividade?

a. As respostas que tiveram destaque foram em relação à atividade ter sido com um assunto fácil de matemática mesmo reconhecendo que não sabiam como se dava o processo de construção da escala ou que matemática era usada para construí-la;

b. Um aluno questionou: e se fosse um assunto mais difícil que não soubessem responder como se sairiam;

c. Outra resposta foi importante por ter a possibilidade de saber como calcular a frequência do som a partir do tamanho da corda e organizar as notas em sequência para formar a escala que vai subindo no som grave.

5. Que tipo de trabalho vocês realizaram?

a. Uma resposta que causou risos: "Descobrimos que tem muita matemática dentro da escala de música";

b. Outras respostas destacaram o fato de no cotidiano eles não perceberem essa relação.

\section{Análise da Atividade}

1. A atividade buscou a presença de contexto para a Matemática, especificamente na compreensão do fenômeno sonoridade musical para construção de uma escala musical.

2. Os contextos vivenciados no desenrolar da atividade estão relacionados ao conhecimento de frações, sucessão e sequência, relação funcional e medidas.

3. Percebemos que outros conteúdos matemáticos relacionados à música apareceram e que ficaram para ser discutidos posteriormente com os cinco estudantes da turma de Prática II que participaram como observadores na atividade, destacando-se:

a. As funções que estabelecem uma relação da variação e intensidades dos sons em função do tempo (relação entre grandezas);

b. Que existe uma rica exposição da notação musical a partir das pautas musicais que remetem a uma conexão com a construção de gráficos e tabelas. Tal fato aparece 
no material elaborado pelos alunos do Ensino Médio, em todos os grupos que participaram da atividade (Figura 4);

c. A elaboração do modelo que representasse a escala musical, construída pelos alunos descrevia o processo de Modelagem que estavam vivenciando como processo metodológico (construção de modelos descritivos de um fenômeno). A partir dos sons identificados e anotados pelos estudantes nas regularidades imputadas pela sonoridade do instrumento, que foi um ponto importante na atividade, pois os alunos se observavam como construtores da escala musical (Figura 4);

d. O tipo de atividade poderia ser levado a uma compreensão de atividade com funções (afim, logarítmica), pois as referências da notação musical e as regularidades constantes relativa a "som/tempo" leva ao conceito de função afim, deixando que os alunos se apropriem da análise de suas propriedades (referência ao comprimento da corda e suas correspondências com as notas musicais). Pode-se ainda explorar o conceito de função logaritmo e a consequente inversão para o conceito de função exponencial, a partir dos cálculos realizado (mas nesse caso não exploramos, apenas comentamos com os alunos de Prática II);

e. Como fato histórico, apesar dos experimentos pitagóricos serem antigos e seus estudos estarem já consolidados, o campo da acústica com variantes para a matemática engloba áreas da tecnologia e do tratamento da informação, que podem servir de mote para se trazer para a sala de aula saberes do campo científico. Nesse caso, o trabalho do professor pode incluir um software de detecção acústica (sons), em que seria trabalhada a produção de gráficos. Neste momento, deve-se contextualizar os dados produzidos com a ferramenta diante de um processo de aplicação prática (apenas comentamos com os alunos de Prática II);

f. A atividade nos fez perceber que um professor poderia fazer uma breve introdução a respeito do pensamento científico, da tradição da civilização grega, entre outros, reproduzindo um experimento com uso de um monocórdio, para explorar as relações inerentes a matemática e a música, como realizado na nossa prática, que buscava entender um processo de contextualização matemática;

g. Pitágoras estudando os tons da escala musical descobriu que a nota determinada pela frequência de uma corda esticada, estava associada com valores de frações obtida dessa frequência, ou seja, a partir da primeira frequência, outras estariam combinadas. Por exemplo, tendo a corda esticada uma frequência de $220 \mathrm{~Hz}$ representando a primeira nota, as notas que tinham maior consonância com a primeira seriam aquelas de frequência $440 \mathrm{~Hz}, 660 \mathrm{~Hz}, 880 \mathrm{~Hz}$, e assim por diante, como destaca Martins (2015). Dessa forma, uma razão existia entre essas frequências, que no caso é de 1:2, hoje chamado de um intervalo de oitava, ou seja, 
estarão situadas dentro de um intervalo de uma oitava, 8 notas (do som inicial até sua repetição Dó, Ré, Mi, Fá, Sol, Lá, Si, Dó). Assim, ao marcar no comprimento da corda, 12 subdivisões iguais, teremos o primeiro som (corda esticada), depois ao prender a corda na metade (1/2) de seu comprimento, obtém-se o mesmo som, só que mais agudo (chamado de oitava), depois prendendo em (3/4) do tamanho da corda que resultou em uma quarta. Ao tocar em (2/3) da corda resultou em uma quinta, Figura 5. Assim, as frações utilizadas seriam 1/2, 3/4, 2/3, que correspondem à oitava, à quarta e à quinta, tinha sons harmoniosos, agradáveis (que são chamados dissonantes).

Outros saberes relativos ao contexto envolvendo a Matemática e Música, que são resultantes da atividade e surgiram posteriormente da pesquisa para o seminário com os estudantes da disciplina de Prática II, que se dispusera a pesquisar e trouxeram as seguintes informações, como forma de complementar o conhecimento gerado, foram:

1. Para representação do aumento da frequência do som no campo de uma oitava trabalha-se bastante com Matemática e pode ser obtido a partir de produto das frações indicadas pelo produto da primeira nota, como destaque: Segunda Maior, Terça Maior, Quarta Justa, Quinta Justa, Sexta Maior, Sétima Maior e Oitava Justa, como na Figura 5, da seguinte forma:

$$
\begin{aligned}
& 1 \times \frac{9}{8}=\frac{9}{8} \rightarrow \text { Segunda Maior } \\
& 1 \times \frac{9}{8} \times \frac{10}{9}=\frac{5}{4} \rightarrow \text { Terça Maior } \\
& 1 \times \frac{9}{8} \times \frac{10}{9} \times \frac{16}{15}=\frac{4}{3} \rightarrow \text { Quarta Justa } \\
& 1 \times \frac{9}{8} \times \frac{10}{9} \times \frac{16}{15} \times \frac{9}{8}=\frac{3}{2} \rightarrow \text { Quinta justa } \\
& 1 \times \frac{9}{8} \times \frac{10}{9} \times \frac{16}{15} \times \frac{9}{8} \times \frac{10}{9}=\frac{5}{3} \rightarrow \text { Sexta Maior } \\
& 1 \times \frac{9}{8} \times \frac{10}{9} \times \frac{16}{15} \times \frac{9}{8} \times \frac{10}{9} \times \frac{9}{8}=\frac{15}{8} \rightarrow \text { Sétima Maior } \\
& 1 \times \frac{9}{8} \times \frac{10}{9} \times \frac{16}{15} \times \frac{9}{8} \times \frac{10}{9} \times \frac{9}{8} \times \frac{16}{15}=2 \rightarrow \text { Oitava justa }
\end{aligned}
$$

Figura 5 - Representação dos indicadores do aumento da frequência do som no espaço de uma

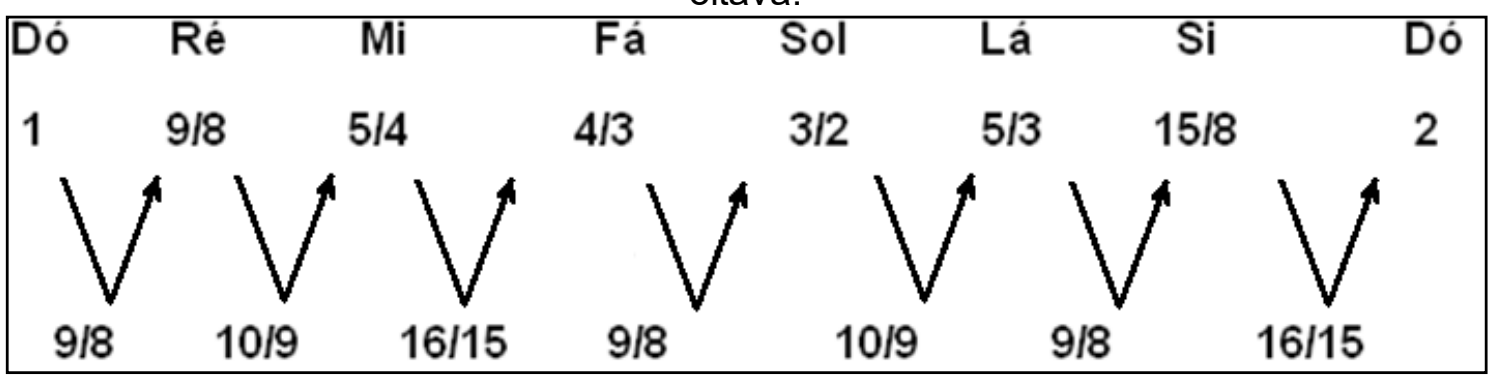

Fonte: Wikipédia. Disponível em:

http://www2.mat.ufrgs.br/edumatec/atividades diversas/razaodiatonica/objetos/escaladiatonica.ht $\underline{\mathrm{ml}}$. 
2. Se tivéssemos um instrumento de cálculo de frequência do som (Osciloscópio ou Diapasão), para comprovar os intervalos entre cada uma das alturas das notas da escala, verificaríamos que existem apenas dois valores fracionários que os representa, ou seja, as frações 9/8 e 256/243 (conforme a Figura 6), que na história da música são chamados de diatônicos ou tom pitagórico e semitom pitagórico. Nessa condição chegamos a escala com as sete notas, mas, entenderíamos melhor utilizando um Osciloscópio para obter os valores de frequência de cada nota produzida no Monocórdio.

Figura 6 - Representação da escala diatônica.

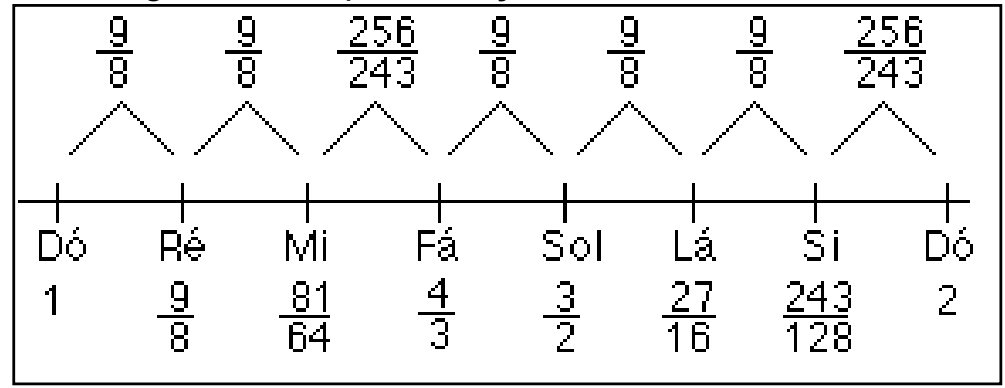

Fonte: lazzetta (2000). Disponível em:

http://www2.eca.usp.br/prof/iazzetta/tutor/acustica/escalas/pitagorica.html.

\section{Resultados e Discussão}

A atividade realizada buscava explorar com os alunos do ensino médio uma proposta de contextualização da matemática a partir da construção da escala musical. Esse tema foi selecionado pelo grupo investigador pelo fato de três componentes desse grupo (dois estudantes Licenciatura em Matemática e o professor pesquisador), já possuírem algum conhecimento básico de música.

Ao apresentar o Monocórdio (objeto não conhecido pelos alunos), observamos que todos ficaram eufóricos em entender que tipo de atividade matemática seria trabalhado. Ao questionarmos sobre quem conhecia a escala musical, todos foram enfáticos em afirmar as notas básicas sem os semitons (Dó Ré Mi Fá Sol Lá Si). Dessa forma, o processo ficou valorizado pela expectativa dos alunos.

Observamos que os estudantes participaram com interesse na atividade, pois buscavam descobrir como chegar à compreensão da escala musical a partir de um instrumento musical, Monocórdio e como a matemática ajudaria nesse processo.

Foi possível observar que, durante a realização do experimento, os alunos tinham interesse em falar sobre a atividade e sobre a importância da relação que estavam verificando entre matemática e música. Observaram que o uso de conhecimento relativo a frações (valor, comparação, adição e multiplicação), estavam sendo aplicados na atividade, dando reconhecimento do contexto criado. Isso ficou evidente no trabalho coletivo e nas discussões que foram presenciadas nos grupos. 
Notamos que foi necessária uma explicação do cálculo fracionário a ser utilizado a partir da medida da corda do monocórdio, ou seja, como deveriam iniciar a atividade de identificação e registro dos valores, que estariam associados às notas musicais, conforme visualizado na Figura 5 .

Durante a atividade, observamos que os alunos buscavam compreender os cálculos necessários que estavam sendo exigidos para a construção da escala, pois essa Matemática ganhava importância pelo fato de não acontecer falhas na construção da escala (Figura 4), e por estar associada a um saber que eles pouco conheciam, que é a sequência das notas da escala musical.

No processo de cálculo se buscava a compreensão de subdivisão da escala. Alguns grupos se depararam com certas dificuldades que são inerentes à atividade, porém, ao discutirem sobre os resultados e sobre a possibilidade de arredondamento de valores, chegavam a uma compreensão para a representação correta dos valores numéricos que definiam os tons da escala.

Posterior à atividade envolvemos os cinco estudantes de Licenciatura em Matemática que participaram como observadores, em um seminário sobre o tema da investigação para complementar os saberes sobre a prática de contextualização da matemática presente na atividade. Evidenciamos contextos e a construção do modelo de escala musical pelos alunos do ensino médio.

A experimentação trabalhada que buscou contextualizar a Matemática por meio da Música respondeu a inquietação dos estudantes de Prática II, pelo fato de passarem a compreender a evidência do fenômeno. Tal experiência foi posteriormente discutida na turma, sob o aspecto de que tal estudo é um exemplo de atividade em que se coleta de dados em projetos de pesquisa na Educação Matemática, em cursos de pós-graduação ou em projetos de PIBIC das universidades. Tal discussão foi levada ao grupo, pois estavam encerrando o curso de Licenciatura em Matemática e alguns já cogitavam em concorrer ao mestrado do Programa de Pós-Graduação em Ensino de Ciências da Universidade - PPGEC/UFRPE.

\section{Referências}

AABOE, A. Episódios da História Antiga da Matemática. Coleção do Professor de Matemática. Rio de Janeiro: SBM, 2002.

ABDOUNUR, O. J. Mudanças Estruturais nos Fundamentos Matemáticos da Música a partir do século XVII: considerações sobre consonância, série harmônica e temperamento. Revista

Brasileira de História da Matemática. Especial n. 1 p. 369-380, 2007.

BASSANEZI, R. C. Ensino-Aprendizagem com Modelagem Matemática. São Paulo: Contexto, 2002.

BOYER, B. C. História da Matemática. São Paulo: Edgard Blücher, 1974.

BRASIL. Ministério da Educação. Secretaria de Educação Básica. Orientações Curriculares para o Ensino Médio. v. 2. Brasília: MEC/SEB, 2006.

BRASIL. Ministério da Educação. Secretaria de Educação Fundamental. Parâmetros curriculares nacionais: Matemática. Brasília: MEC/SEF, 1997. 
BRASIL. Ministério da Educação. Secretaria de Educação Fundamental. Parâmetros curriculares nacionais: Matemática. Brasília: MEC/SEF, 1998.

BRASIL. Presidência da República. Casa Civil. Lei nº 9.394, de 20 de dezembro de 1996. Estabelece as diretrizes e bases da educação nacional. Brasília, DF, 1996.

BROUSSEAU, G. Os diferentes papéis do professor. In: PARRA, C.; SAIZ, I.; et al. (Orgs.). Didática da Matemática: Reflexões Psicopedagógicas. Porto Alegre: Artes Médicas, 1996.

BORIN, J. Jogos e resolução de problemas: uma estratégia para as aulas de matemática. São Paulo: IME-USP, 1996.

DEMO, P. Professor do Futuro e Reconstrução do Conhecimento. Petrópolis, RJ: Vozes, 2004.

EVES, H. Introdução à História da Matemática. 2. ed. Campinas: Unicamp, 1997.

FLAVELL, J. H. El Desarrollo Cognitivo. Madrid: Visor, 1976.

FRANCHI, R. H. de O. L. A Modelagem Matemática como estratégia de aprendizagem do cálculo diferencial e integral nos cursos de engenharia. 1993. 148f. Dissertação (Mestrado em Educação Matemática) - Instituto de Geociências e Ciências Exatas, Universidade Estadual Paulista, Rio Claro, 1993.

MARTINS, D. F. de P. S. Escalas, Inversas e Tríades: A Matemática aplicada à Música. 2015. 60f. Dissertação (Mestrado em Matemática) - Centro de Ciências e Tecnologia, Universidade Estadual do Norte Fluminense Darcy Ribeiro, Campos dos Goytacazes, Rio de Janeiro, 2015.

NASCIMENTO, R. A.; GITIRANA, V. Modelagem Matemática. Projeto Rede: Jogos na Educação Matemática. Universidade Federal de Pernambuco. Centro de Educação, 2011. Disponível em: <http://www.lematec.net.br/CDS/SJSEM/artigos/modelagem.pdf>. Acesso em: 12 out. 2012.

PAVANELLO, R. M. Contextualizar: O que é isso? In: NOGUEIRA, C.; BARROS, R. (Orgs.). Conversas com quem gosta de ensinar matemática. Paraná: Manoni, 2004.

SKOVSMOSE, O. Educação matemática crítica: a questão da democracia. Campinas, SP: Papirus, 2001.

VASCONCELOS, M. B. F. A Contextualização e o Ensino de Matemática: Um Estudo de Caso. 2008. 249 p. Dissertação (Mestrado em Educação Popular, Comunicação e Cultura) Universidade Federal da Paraíba, 2008. 